NBER WORKING PAPER SERIES

\title{
HOW DO WORKPLACE SMOKING LAWS WORK? QUASI-EXPERIMENTAL EVIDENCE FROM LOCAL LAWS IN ONTARIO, CANADA
}

\author{
Christopher Carpenter \\ Working Paper 13133 \\ http://www.nber.org/papers/w13133
}

\section{NATIONAL BUREAU OF ECONOMIC RESEARCH \\ 1050 Massachusetts Avenue \\ Cambridge, MA 02138}

May 2007

Carpenter is Assistant Professor of Economics/Public Policy, The Paul Merage School of Business at UC Irvine, kittc@uci.edu, 443 SB UC Irvine, Irvine, CA 92697-3125. These results are based on data from the CAMH Monitor and are protected by a confidentiality agreement. Interested readers can contact the author for details on how to request access. I am grateful to Anca Ialomiteanu and Ed Adlaf for assistance with the data. Marianne Bitler, Tom Buchmueller, Phil DeCicca, Mireille Jacobson, David Neumark, Mark Stehr, and Madeline Zavodny provided very useful comments on previous drafts. I am also grateful for comments from seminar participants at the NBER, the Paul Merage School of Business, the 2006 Canadian Health Economics Study Group Meetings, the 2006 American Society of Health Economists Meetings, and the University of South Florida. All errors are my own. The views expressed herein are those of the author(s) and do not necessarily reflect the views of the National Bureau of Economic Research.

(C) 2007 by Christopher Carpenter. All rights reserved. Short sections of text, not to exceed two paragraphs, may be quoted without explicit permission provided that full credit, including $\odot$ notice, is given to the source. 
How Do Workplace Smoking Laws Work? Quasi-Experimental Evidence from Local Laws

in Ontario, Canada

Christopher Carpenter

NBER Working Paper No. 13133

May 2007

JEL No. I1,J08

\begin{abstract}
There are very large literatures in public health and economics on the effects of workplace smoking bans, with most studies relying on cross-sectional variation. We provide new quasi-experimental evidence on the effects of workplace bans by using the differential timing of adoption of over 100 very strong local smoking by-laws in Ontario, Canada over the period 1997-2004. We employ restricted-use repeated cross section geocoded outcome data to estimate reduced form models that control for demographic characteristics, year fixed effects, and county fixed effects. We first show that the effects of the local laws on actual worksite smoking policy (i.e. the "first stage") were not uniform; specifically, local laws were only effective at increasing ban presence among blue collar workers. Among blue collar workers, adoption of a local by-law significantly reduced the fraction of worksites without any smoking restrictions (i.e. where smoking is allowed anywhere at work) by over half. The differential effect of local policies also improved health outcomes: we find that adoption of a local by-law significantly reduced SHS exposure among blue collar workers by 25-30 percent, and we confirm that workplace smoking laws reduce smoking. We find plausibly smaller and insignificant estimates for white collar and sales/service workers -- the vast majority of whom worked in workplaces with privately initiated smoking bans well before local by-laws were adopted. Overall our findings advance the literature by confirming that workplace smoking bans reduce smoking, documenting the underlying mechanisms through which local smoking by-laws improve health outcomes, and showing that the effects of these laws are strongly heterogeneous with respect to occupation.

Christopher Carpenter

University of California, Irvine

The Paul Merage School of Business

$443 \mathrm{SB}$

Irvine, CA 92697-3125

and NBER

kittc@uci.edu
\end{abstract}


California recently became the first state to classify secondhand smoke (SHS) as a toxic air pollutant, with potentially wide ranging policy implications. This recent activity, however, is part of a much more longstanding trend in recognizing the potential health risks associated with SHS. One of the most important ways this sentiment has been exhibited in the US is though the steady increase in restrictions on smoking at private worksites: by 1999 almost 70 percent of adult workers reported the presence of a complete work area smoking ban (Shopland et al. 2001). A large literature in the US has examined the effects of these workplace restrictions: multiple reviews of the evidence find that workplace smoking bans are associated with reduced exposure to secondhand smoke (SHS) and lower rates of own smoking and per capita cigarette consumption (Fichtenberg and Glantz 2002, Levy and Friend 2003, Brownson et al. 2002, and others).

An increasingly common policy tool aimed at achieving these improved outcomes is the adoption of local laws requiring smoke-free workplaces. These policies are widespread in the US: as of 2005, 328 municipalities have adopted 100\% smokefree workplace laws (Americans for Nonsmoker's Rights 2006), and if one includes less restrictive policies the number of smokefree ordinances is well over 1000 (Brownson et al. 2002). Moreover, the trend in adoption of local ordinances has been steadily upward, a phenomenon that has also occurred across Canada. Although a handful of US states and Canadian provinces have recently adopted tough 100\% smoke-free workplace laws, it has been hypothesized that adoption of local laws may engender stronger community support than larger scale efforts, thereby increasing compliance (Levy and Friend 2003).

Previous public health research on the effects of these local policies generally follows a cross-locality research design, in which outcomes (smoking, SHS exposure) for residents of 
cities with smoking by-laws are compared to outcomes for residents in untreated areas. These studies typically find that individuals living in cities and towns with strong local ordinances have better outcomes than otherwise similar individuals living in areas without such policies or with weaker policies. These cross-locality research designs may be problematic, however, if there exist unobserved characteristics about people that are correlated both with the decision to adopt a smoking ordinance and with individual preferences regarding smoke-free worksites and/or own smoking behavior. Since the usual set of control variables available to researchers in the datasets used in these studies is fairly limited, these biases generally cannot be ruled out. In this paper we revisit the effects of local smoking policies by using a quasi-experimental research design applied to the case of Ontario, Canada - the most populated province in that country - over a period of rapid and widespread adoption of local smoking by-laws. In so doing, our goal is to provide new evidence on the effects of local smoking ordinances on actual ban presence, secondhand smoke exposure, and own smoking outcomes.

Our study makes several distinct contributions to the existing literature. First, we provide direct estimates of the extent to which local workplace smoking by-laws actually affect reported work ban presence. While this may seem obvious, a review of the literature suggests this is not the case: very little of the public health research and none of the economics studies on this topic examine actual compliance by worksites. ${ }^{1}$ Since a necessary condition for these local ordinances to improve health outcomes is that they must be adopted by worksites, this is an independently worthwhile endeavor. Indeed, local by-laws might not translate into increased worksite policies because of lack of compliance or enforcement. Our data on worksite smoking policies allow us to evaluate whether local by-laws mainly affect the extensive margin (by increasing the

\footnotetext{
${ }^{1}$ Notable exceptions are Pierce et al. (1994) and Moskowitz et al. (2000). Both of these studies use a cross-sectional research design.
} 
likelihood of reporting any workplace smoking restriction) or intensive margin (by increasing the intensity or strength of existing workplace smoking bans).

Second, our analysis of local smoking ordinances explicitly accounts for time-invariant unobserved heterogeneity through the inclusion of county fixed effects. Most previous research either does not control at all for area effects or does so at a much broader level (e.g. state). In this respect, our use of a well-accepted two-way fixed effects methodology marks a notable improvement over much of the previous literature in public health and economics on local clean indoor air laws.

Third, this study is - to our knowledge - the first to consider the effects of smoking ordinances separately by white collar and blue collar occupations. Although it has been previously documented that blue collar workers have poorer SHS and own smoking outcomes compared to white collar workers (see, for example, Wortley et al. 2002, and Gerlach et al. 1997), the existing literature on this topic is almost entirely descriptive in nature. Our results uncover the first evaluative evidence that local smoking ordinances were especially effective at improving outcomes for blue collar workers and essentially ineffective at improving outcomes for other types of workers. ${ }^{2}$

Finally, our research design allows us to provide complementary evidence on the important question of whether workplace smoking bans reduce smoking. Although most data sources show a large negative cross-sectional relationship between the presence of a work area smoking ban and individual smoking participation, there are reasons to be skeptical that those

\footnotetext{
${ }^{2}$ Our study also offers one of the first large scale analyses of the effects of smoking bans in Canada. Although a handful of Canadian studies have considered sector-specific (e.g. office buildings), single-site, or single-city evaluations in cities in Canada, it is not obvious that those results generalize more broadly (Broder et al. 1993, Hammond et al. 2004). The general paucity of Canadian studies is notable given that workplace smoking restrictions have proliferated in the country in the past decade and given the enormous growth of the US-focused literature.
} 
single equation estimates reflect true causal effects (e.g. unobserved factors that may be correlated with both smoking decisions and workplace characteristics). Previous research has attempted to deal with this problem by using firm characteristics as instruments for workplace smoking bans and finds very little evidence of an omitted variables bias (Evans et al. 1999). Our use of the differential timing of adoption of local smoking by-laws provides an interesting complementary way to estimate whether plausibly exogenous variation in workplace smoking bans generated by these local by-laws is associated with predictable declines in smoking participation.

Our analyses use restricted-use repeated cross section data from the 1997-2004 CAMH Monitor (formerly the Ontario Adult Drug Monitor). These data provide information on individual outcomes both before and after the implementation of over 100 local smoking by-laws within Ontario. Importantly, these data also identify the respondent's detailed location of residence, which we use to match the local smoking restrictions to the individual observations. Our preferred approach estimates the effects of local smoking restrictions in the presence of controls for demographic characteristics, survey year dummies, and county fixed effects.

To preview, we find that adoption of local smoking bans in Ontario significantly increased reported ban presence. In the full sample, a local by-law is estimated to increase the likelihood of reporting a complete work area ban by about seven percent. We also find large estimated reductions in the likelihood of reporting that smoking is allowed "anywhere" at work (i.e. no workplace restrictions). These aggregate effects, however, mask important differences associated with occupation. Specifically, the effects of by-laws on ban presence are driven entirely by blue collar workers. Among blue collar workers we find that adoption of a local bylaw cuts the likelihood of reporting no workplace policy by about half and increases complete 
ban presence by about 25 percent. We also find a significant reduction in SHS exposure of about 25-30 percent and a large estimated reduction in own-smoking rates for blue collar workers. Importantly, our estimates for outcomes of white collar and sales/service workers - whose worksites were much more likely to have privately initiated smoking bans in the pre-reform period - are plausibly smaller and statistically insignificant.

Taken together, our results confirm the beneficial effects of local clean indoor air laws and by implication workplace smoking bans - on respiratory health but uncover substantial occupation-related heterogeneity in their effects. From a policy perspective, this suggests that recent movements toward occupation-specific bans focusing on bars and restaurants may have overlooked factories and warehouses as equally important targets of reform. And from a methodological standpoint, our results are important because they provide initial insight into the potential effects of a province-wide smoking ban that went into effect in Ontario in 2006. Since other states and provinces have similarly adopted wide ranging smoking ordinances, it is particularly important to understand extent to which pre-existing local by-laws have already improved worker outcomes. Failing to do so could result in biased estimates of the effects of state or province-wide policies.

The paper proceeds as follows. Section II provides a brief review of relevant literature. In Section III we present the data and outline the empirical approach, and Section IV offers the main results. Section V concludes.

\section{Previous Research}

A very large body of economics and public health literature has considered the effects of workplace smoking bans. In fact, multiple reviews of the literature have been published in the 
past 5 years. These reviews generally focus on the effects of smoking bans on smoking behavior and SHS exposure (see, for example, Fichtenberg and Glantz 2002, Levy and Friend, 2003, and Brownson et al. 2002). An example is Evans et al. (1999) who use multiple US sources of data on privately initiated workplace smoking bans in the early 1990s and find a strong negative relationship between a workplace smoking ban and smoking participation and intensity. To address concerns about unobserved third factors such as preferences for risk or health that may bias the cross-sectional relationships, these researchers use firm size as an instrumental variable and find that the IV estimates of the effect of smoking bans on own-smoking are slightly larger than the OLS estimates, suggesting a causal effect of bans at reducing smoking.

Most economics research on the effects of smoking bans, however, considers the effects of public policies that restrict smoking in various settings. Wasserman et al. (1991), for example, use several waves of the National Health Interview Survey from 1970-1985 and append state smoking regulations to the individual level data. They control for a state-specific index that is larger if smoking is restricted in private worksites and smaller if smoking is restricted, say, only in restaurants or elevators. Results indicated that higher state smoking restrictions were negatively related to tobacco consumption. Keeler et al. (1993) also control for a local smoking regulations index in California that adjusted for exposure in a manner similar to the Wasserman et al. study; they also find some evidence that local ordinances reduced cigarette consumption. Chaloupka (1992) uses data from NHANES II and controls for the extent of workplace smoking restrictions at the state level. He finds that state clean indoor air laws are associated with lower cigarette consumption, with results driven mostly by males. Yurkeli and Zhang (2004) use state panel data on cigarette sales in the US from 1970-1995 and control for clean indoor air laws through the use of an index similar in spirit to those described above. Tauras (2005) applies a 
similar framework to microdata from the Tobacco Use Supplements of the Current Population Survey over the period 1992-1999. Importantly, both Yurkeli and Zhang (2004) and Tauras (2005) include unrestricted state and year fixed effects, and both find that the clean indoor air laws are significantly and negatively related to cigarette consumption.

Nearly all public health research on this topic uses a cross-locality research design to study the effects of local smoking restrictions. Moskowitz et al. (2000), for example, use a single cross section of the 1990 California Tobacco Survey and append independently coded data on the strength of local workplace ordinances. They find that, among individuals who were smokers or who had smoked in the 6 months prior to the survey, residents in areas with strong ordinances were significantly more likely to report the existence of a worksite smoking policy and to report quitting behavior compared to residents of areas with no local ordinance. Emont et al. (1992) perform a similar exercise using variation in the strength of state level restrictions and the 1989 Cardiovascular Disease Supplement to the Current Population Survey. They find that residents of states with more restrictive laws had lower cigarette consumption and higher quit rates than residents of states with less restrictive laws.

There is much less research on the effects of smoking laws in Canada. Stephens et al. (1997) used a cross-sectional data set of Canadian residents in different provinces and compared residents in areas with "extensive" and "weak" coverage of smoking by-laws in 1990/91; they found that individuals in extensive coverage areas had 21 percent lower odds of being a current smoker compared to individuals in areas with weak coverage. ${ }^{3}$ Another recent Canadian study

\footnotetext{
${ }^{3}$ That study, however, included any municipal by-law that restricted smoking. Indeed, their by-law data show that fully $76 \%$ of Ontario residents were covered by a municipal by-law that restricted smoking as of 1991 . It is likely that these included much less extensive restrictions such as Toronto's 1970's law that banned smoking in elevators, escalators, and service line-ups. Our approach, in contrast, focuses only on by-laws with substantial worksite smoking restrictions. As indicated by independent data from the Ontario Tobacco Action Network (described below), these did not proliferate across Ontario until the late 1990s.
} 
used a telephone survey of former smokers in Waterloo, Ontario and information on the timing of when they quit smoking to assess whether the city's smoke-free by-law played any role in helping smokers quit (Hammond et al. 2004). Using self-reported assessments of the importance of the smoke-free by-law, the researchers conclude that more stringent smoke-free policies "were associated with a greater impact upon motivations to quit."

To summarize, there is a large body of evidence on the question of whether smoking bans improve worker outcomes and on the effects of clean indoor air legislation. Our study differs from the previous literature in the following ways: 1) we are most interested in tough $100 \%$ completely smoke-free local by-laws as opposed to less restrictive policies pertaining to other public spaces; 2) unlike the majority of the economics studies, we consider only consider local laws, which allows us to abstract away from prices and policies that vary at the broader state or provincial level (e.g. cigarette taxes); 3) unlike the public health literature on local smoking laws, we explicitly account for time-invariant unobserved heterogeneity through inclusion of county fixed effects; 4) we are explicitly interested in the "first stage" relationship between smoking laws and actual reported worksite smoking policies; and 5) we provide the first estimates of the effects of local by-laws and smoking bans by broad occupation group. ${ }^{4}$

\section{Data Description and Empirical Approach}

Our outcome data come from restricted use versions of the 1997-2004 CAMH Monitor. The CAMH monitor is a telephone survey administered throughout the calendar year. These data are repeated cross sections of approximately 2300 adults in Ontario each year and contain detailed

\footnotetext{
${ }^{4}$ Again, we note that others have previously investigated the role of occupation, though not in an evaluative context. Wortley et al. (2002), for example, found heightened serum cotinine levels - a biological marker of SHS exposure among operators, fabricators, and laborers. Gerlach et al. (1997) find that construction trades workers, fabricators,
} 
geographic information on the respondent's residence as measured by the first three characters of the individual's self-reported postal code. The CAMH monitor also includes standard demographic characteristics for all respondents, such as: age, sex, marital status, and education. We control for these demographic characteristics in the regression models below.

In each year a subset of the core sample was asked a set of questions about tobacco policy, including smoking restrictions at their workplace. Individuals are first asked whether they work outside the home, and if so what the smoking restrictions are at their place of work. ${ }^{5}$ Specifically, respondents are asked, "Which of the following statements describes the policy on smoking where you work? One: Smoking is allowed anywhere. Two: There are smoking areas indoors. Three: Smoking is only allowed outside. Or Four: Smoking is not allowed at all. Not allowed at all means no smoking on company property, both indoors and outdoors." We first define an outcome called No Workplace Policy equal to one if the individual reports that smoking is allowed anywhere and zero otherwise. This outcome is meant to asses whether local ordinances affect the extensive margin by inducing some worksites with no workplace policy to adopt some nontrivial restriction. We next create an indicator called Ban Presence equal to one if the individual reports that smoking is completely banned on company property or if smoking is only allowed outside and zero otherwise. ${ }^{6}$ Finally, we use the range of responses described above to create a simple index called Ban Range that equals 1 if smoking is allowed anywhere at

machine operators, and mechanics had some of the lowest smoke-free workplace coverage in the 1992/93 Tobacco Use Supplements to the Current Population Surveys.

${ }^{5}$ Later in the survey adults are also asked about their detailed labor force status, including: full-time or part-time job, sick leave, unemployed, retired, homemaker, student, or self-employed. We restrict attention to full-time workers, part-time workers, and those who say they have a job but are currently away from it (for example because of sick leave or vacation).

${ }^{6}$ Because the response options in the CAMH monitor are slightly different than associated options in US data (such as the National Health Interview Survey), our "Ban Presence" outcome should most closely be thought of as a complete "work area smoking ban" such as those used by Evans et al. (1999). Note also that most US data sources only ask the workplace smoking restriction question to those who work indoors; there is no such sample restriction 
work, 2 if there are smoking areas indoors, and so forth. Throughout, we assume that respondents report their current workplace smoking policy. This seems warranted given the wording of the question.

Individuals are also asked about exposure to secondhand smoke at their place of work. Specifically, individuals are asked: "In the last week, how many days were you exposed to other people's [emphasis added] tobacco smoke while you were at work? By exposed, I mean spending at least 5 minutes in an area where someone is smoking." We create an outcome variable called No SHS equal to one if the respondent reports zero days of exposure to SHS at work and zero otherwise. We also create a variable called Daily SHS Exposure that equals one if the respondent reports exposure to other people's SHS on 5 or more days in the last week. Our use of self-reported days of exposure is supported by previous research which demonstrates that these self-reported outcomes are strongly correlated with other biological markers of environmental tobacco smoke such as ambient nicotine measurements (Coghlin et al. 1989). ${ }^{7}$ Finally, we use information on the respondent's own smoking behavior to create a dummy variable indicating the respondent is a Current Smoker. ${ }^{8}$

Our local workplace smoking restriction data are publicly available and come from a publication entitled "Municipal Smoke-Free Bylaws in Ontario" from the Ontario Campaign for Action on Tobacco (www.ocat.org). This organization tracks the implementation dates of the

used in the CAMH monitor. If anything, this should bias us against finding effects, since individuals who should plausibly not be affected by the local ordinances are unfortunately included in the sample.

${ }^{7}$ Importantly, the CAMH monitor question on SHS exposure provides a specific, objective outcome measure of SHS exposure that does not require knowledge about the official smoking policy at the worksite. That is, even individuals responding that they did not know the policy on smoking at their worksite gave valid responses to questions about SHS exposure. This marks a notable improvement of the CAMH monitor over other similar data sources in the US such as the Tobacco Supplements to the Current Population Survey, which only asks the questions about SHS exposure to those who report the presence of an official workplace smoking policy. Since it is possible that one might detect the effects of a ban on reported SHS exposure but not ban presence, the CAMH monitor questions are likely preferred. In practice, however, the number of "don't know" responses to the question about workplace smoking policy is too small to have substantive effects on our estimates. 
local bylaws in Ontario and also indicates whether the ordinance permits Designated Smoking Rooms (DSRs) or requires 100\% compliance with smoke-free areas. We match the localities covered by workplace smoking bans in the OCAT according to the geographic residence information provided in the CAMH monitor, and we create a variable called Workplace By-Law that equals one if the individual's residence is covered by a local ordinance that requires workplaces to be $100 \%$ smoke-free and zero otherwise.

Our main empirical approach is two-way fixed effects, in which the change in outcomes (ban presence, days of SHS exposure, and own smoking behavior) of individuals living in banadopting areas around the time of ban implementation are compared to the associated changes in outcomes for otherwise similar individuals living in areas in Ontario that did not adopt a ban at the same time. The key identifying assumption in this model is that there were no other shocks at the same time of the implementation of the ban that differentially affected outcomes. This difference-in-differences approach addresses unobserved area-specific heterogeneity through the inclusion of county fixed effects.

We implement the basic model by estimating the following reduced form regression on the sample of adults who report working outside the home and have no missing data on the demographic characteristics or outcome variables:

(1) $Y=\alpha+\beta_{1} X+\beta_{2}$ (Local Workplace By-Law) + County + Survey Year $+\varepsilon$

where Y refers to the various outcomes described above. We use linear probability models (LPM) for the dichotomous outcomes for simplicity. ${ }^{9} \mathrm{X}$ is a vector of demographic information that includes: age, sex, marital status ( 3 categories), and education (4 categories). Area is a vector of dummies for either postal code, county, or region (depending on the model), while

\footnotetext{
${ }^{8}$ Smoking intensity is only observed for daily smokers, so we do not analyze it here.

${ }^{9}$ Probit results were very similar and are available upon request.
} 
Survey Year is a vector of survey year dummies. Local Workplace By-Law is an indicator variable equal to one if the respondent lives in a place covered by a relevant local smoking law. The coefficient of interest, $\beta_{2}$, captures the effect of the local bans as measured by the change in outcomes for individuals living in the treated areas relative to the associated change in outcomes for individuals living in non-treated areas. All models use the sampling weights provided by the CAMH monitor, and we cluster standard errors by county (Bertrand, Duflo, and Mullainathan 2004). ${ }^{10}$

Note that our baseline model includes county fixed effects as opposed to, say, postal code or region. ${ }^{11}$ Although such models produced similar results, our focus on county derives from the fact that it is the most common sub-provincial level at which health policies such as workplace smoking by-laws are set in Ontario. Although some small towns adopted $100 \%$ smoke-free ordinances, the large share $(70 \%)$ of our Workplace By-Law indicator is composed of ordinances set at the county level. Of course, we still make use of the postal code information to account for the handful of towns and large cities at the sub-county level that also adopted smoke-free ordinances (e.g. Windsor) but that would not be appropriately captured by a countyspecific algorithm. Unfortunately, "cities" and "towns" - unlike counties - are not identified in the CAMH monitor. Although we could aggregate postal codes to create such measures, this would be incomplete and subjective. Finally, information on postal code is missing for approximately two percent of the sample; in contrast, we observe the county for each respondent.

One limitation of the data in the context of evaluating the effects of local smoking bylaws is that the CAMH monitor identifies the location of the respondent's residence, not the

\footnotetext{
${ }^{10}$ Note that for the model predicting smoking status we do not control for other tobacco policies such as cigarette excise taxes. These policies generally vary at the provincial (as opposed to county) level. We assume such policies affect all Ontario residents equally.
} 
location of work. This is a common problem in evaluations such as ours - including all the related public health literature cited above - and there is little we can do to correct for this slippage. If home/work travel patterns in Ontario are similar to those for its neighbors in the United States, however, this is unlikely to seriously bias our estimates; almost three quarters of adults in the United States live and work in the same county (US Census Bureau 2006). We provide a map of Ontario and its county borders in Figure $1 .{ }^{12}$

Another data issue worth noting is that that the questions about workplace bans and SHS exposure were only asked of a random subset of respondents in each year. Because of this, we can only estimate the effect of local bans on reported ban presence and SHS exposure for a subset of the CAMH respondents. In contrast, the questions about own smoking behavior were asked of all adults. If we are willing to assume that the effect of the local bans on reported ban presence is the same for the respondents who were not asked the questions about workplace smoking restrictions - as seems reasonable - then we can still estimate the reduced form effect of local policy adoption on own smoking outcomes for the entire sample and benefit from the increased precision afforded by having essentially twice as many observations as for the analyses of ban presence. We pursue this approach below. ${ }^{13}$

\section{Results}

${ }^{11}$ Technically, Ontario's "counties" are a combination of counties, districts, regional municipalities, and other governmental designations. Throughout, however, we use the "county' variable in the CAMH monitor data.

${ }^{12}$ We do not know the associated figure for Ontario because county identifiers are not available in the public use versions of the Canadian Census. As in the US, there is substantial heterogeneity in the size of Ontario counties. To provide a sense of this, note that $90 \%$ of Ontario's land area but only about $7 \%$ of its population is represented in the Northern part of the province. In Southern Ontario, counties are smaller and more densely populated. Toronto, Ontario's most populated city, covers about 700 square kilometers; its surrounding municipalities are York (1760 $\left.\mathrm{km}^{2}\right)$, Peel $\left(1240 \mathrm{~km}^{2}\right)$, and Durham $\left(2500 \mathrm{~km}^{2}\right)$. As a point of comparison, the average land area of the 83 counties in Michigan (Ontario's US neighbor to the west and south) is about $1,700 \mathrm{~km}^{2}$. 
We present descriptive statistics for the main sample and separately by the presence of a local workplace smoking by-law in Table $1 .^{14}$ The patterns suggest that localities adopting by-laws are somewhat different from non-adopters: individuals living in areas covered by a workplace by-law are more highly educated, less likely to be married, and less likely to be laborers. We also provide means for the relevant outcomes pertaining to workplace bans, SHS exposure, and own smoking. These patterns provide suggestive evidence that local by-laws may have improved outcomes: workers in areas with a by-law are more likely to report a work area ban on smoking and less likely to report the absence of any workplace smoking restrictions. Workers in areas with local by-laws are also more likely to report zero days of SHS exposure and less likely to report daily SHS exposure. Finally, workers in areas with local by-laws have lower ownsmoking rates than workers in areas without such by-laws. We investigate whether these mean differences in outcomes survive regression adjustment and controls for unobserved area heterogeneity in our regression models below.

An important first step in evaluating the effectiveness of local smoking by-laws in Ontario is showing that they affected respondents' reports of smoking restrictions at their place of work. Indeed, a key goal of our research is to provide evidence on the underlying mechanisms through which local ordinances affect actual adoption of workplace bans. If the local laws did not affect worker reports of ban presence - due, for example, to noncompliance then our research design would have little power to answer questions regarding the effects of these laws on other outcomes such as SHS exposure (distinct from reported ban presence) and own smoking behavior. We address this first question in Table 2, which shows the LPM

\footnotetext{
${ }^{13}$ Moreover, it is not always the case that the same respondents were asked about both workplace bans and SHS exposure. As such, we also estimate the SHS exposure models on the sample of all individuals who were asked the SHS exposure questions, again assuming that the effect of local by-laws on ban presence is constant.
} 
estimates of the effects of local smoking by-laws on reported ban presence over the period 19972004.

The format of Table 2 is as follows: we present OLS results for the likelihood of reporting a complete ban on smoking in one's work area in the top panel, results for an index of smoking restrictions called Ban Range in the middle panel, and results for the likelihood of reporting that smoking is allowed anywhere at work (i.e. no restriction) in the bottom panel. In Column 1 we report results from the model that includes demographic controls, year fixed effects, and county fixed effects for the full sample. Columns 2 and 3 perform the same exercise for the subsample of males and females, respectively.

The estimates in Table 2 provide evidence that the local restrictions represent a true "program": local smoking by-laws are associated with a statistically significant increase in the likelihood an individual reports a work-area smoking ban in the full sample. Relative to a prereform mean of .70 , our results suggest that local by-laws increase ban presence in the aggregate by about 5.5 percent. ${ }^{15}$ The middle panel presents results for the Ban Range outcome and again provides evidence of a significant increase in workplace bans associated with local by-laws; finally, in the bottom panel we find that a local by-law significantly reduces the likelihood that an individual reports that "smoking is allowed anywhere" at work by about 2.4 percentage points. In Columns 2 and 3 we confirm the pattern in previous research (Chaloupka 1992) that there are sex-differences in the responsiveness to clean indoor air laws. Stratifying the sample by sex shows that these increases in ban presence are driven mostly by males - all of the bylaw estimates for males are larger than the full sample estimate and highly significant. In contrast,

\footnotetext{
${ }^{14}$ The sample includes only those respondents with valid responses to the workplace smoking ban question (i.e. the sample excludes nonworkers), though sample characteristics for the full sample were very similar.
} 
estimates for females in the rightmost columns are much smaller, wrong-signed, and always insignificant.

In Table 3 we further investigate the nature of relationship between local by-laws and workplace smoking policies. Specifically, we stratify the sample into two broad types of occupations: blue collar workers (Column 1) and other workers (Column 2) - including professionals, administrative workers, clerical workers, and sales workers - which we defined using the broad occupation code available in the CAMH monitor data. Blue collar workers have been previously identified in public health research as being at especially high risk for SHS exposure (Gerlach et al. 1997 and others). ${ }^{16}$

What is first apparent from Table 3 is that mean outcomes in the pre-reform period were consistently worse for blue collar workers in comparison to other workers: laborers were over 20 percentage points less likely to report a work area ban and over 5 times more likely to report the absence of any worksite smoking restriction in the pre-reform period. Moreover, the estimated effect of the local workplace by-laws in Column 1 of Table 3 is consistently large and statistically significant with respect to all three workplace ban outcomes. This is particularly true for the extensive margin in the bottom row: adoption of a local by-law in Ontario reduced the likelihood of reporting that smoking is allowed anywhere at work by over 50 percent. This result is supported visually in Figure 2, which shows that workplace policies were actually worsening among these workers until the period of widespread by-law adoption starting around 2000 . We

\footnotetext{
${ }^{15}$ We present an expanded set of coefficient estimates for this model in Appendix Table 1. The control variables entered as predicted: there is an increasing trend in ban presence over time, males are less likely to work at sites that ban smoking, as are more highly educated workers.

${ }^{16}$ While food service workers have also been shown to have heightened risk, there are simply too few of these types of workers to provide a meaningful analysis using the CAMH monitor data. There are only 139 workers who could arguably be classified as "food service" workers (e.g. bartenders, waiters/waitresses, cooks, kitchen helpers, etc.) in the CAMH monitor over this entire time period. A model predicting the presence of a workplace smoking ban returned a large positive coefficient on the local by-law indicator indicating an increase of about 35 percentage
} 
also find a statistically significant increase in the likelihood of reporting a work area smoking ban on the order of 20 percent (top panel), and the results on the ban range index (middle panel) are similarly positive and statistically significant. For non-blue collar workers in Column 2 we find no evidence that local by-laws improved any of the measures of ban presence: all of the estimates for these other workers are small and statistically insignificant.

The results in Table 3 therefore demonstrate that local smoking by-laws largely leveled the playing field between white collar and blue collar workers by inducing worksites such as factories and warehouses to adopt a workplace smoking policy. This is also apparent in the raw trends in outcomes presented in Figure 4, which shows that the gap in work area bans just before the main period of local by-law adoption (2000-2004) was well over 30 percentage points but fell to just around ten percentage points by the end of the sample period during a time of widespread local by-law adoption.

In Table 4 we investigate the robustness of the result that local by-laws in Ontario increased reported ban presence by laborers. Like the previous tables, the top panel of Table 4 reports results for the work area ban outcome, the middle panel reports results on the ban range outcome, and the bottom panel reports estimates for the "no work restrictions" indicator. In Column 1 of Table 4 we present models that exclude residents from the regional municipalities (aka counties) surrounding Toronto (York, Peel, and Durham). These workers may be differentially likely to commute into Toronto for work; as such, excluding residents of the areas surrounding Toronto may alleviate concerns about the work/home slippage described above. Doing so returns estimates that are very similar to the baseline (all by-law coefficients are large and significant), providing suggestive evidence that work/home slippage is unlikely to bias our

points (a 75\% increase relative to pre-reform levels), but the estimate was only statistically significant at the 10 percent level. These results are available upon request. 
estimates of the effect of workplace by-laws. In Column 2 we report results from a model where we only controlled for county level by-laws, ignoring the many small towns and even major cities (such as Windsor) at the sub-county level that adopted workplace by-laws. Although we have no reason to believe that the sub-county by-laws were not binding - indeed, this is a key reason we are interested in sub-provincial policies in the first place - doing so may permit a cleaner interpretation of our results with county dummies and alleviates the work/home postal code slippage. Overall, the estimates are little changed and remain statistically significant across the three outcomes.

In Column 3 we restrict attention to individuals whose county or postal code of residence indicates that they live in a place that ever adopted a local by-law over the sample period. Ensuring that the treatment effect estimate is driven by individuals in these "changer" communities is a standard robustness exercise, and the estimates in Column 3 confirm that the main results are not driven by worse outcomes in "control" areas when by-laws are adopted. Column 4 reports results from a model that restricts attention to the period of widespread by-law adoption (2000-2004) and returns larger estimates than the baseline that remain highly significant. Finally, in Column 5 we allow for county-specific linear time trends in addition to county fixed effects. This is a common way to account for unobserved area-specific characteristics that are likely to trend smoothly over time, such as anti-smoking sentiment (Friedberg 1998). Again, all of our main results are similar in magnitude to the baseline estimates and retain statistical significance at standard confidence levels.

The results of Tables 3 and 4, then, confirm that local workplace smoking by-laws in Ontario were most (indeed, only) effective at improving worksite smoking policies among workers in blue collar occupations. Workers in other occupations, in contrast, were much more 
likely to have worked at job sites that restricted smoking (e.g. offices) well before the period of local by-law adoption; the local ordinances in Ontario appear not to have been binding for these individuals. This finding provides important information on the plausibility of estimates regarding the effects of local by-laws - and by implication workplace smoking bans - on outcomes such as SHS exposure and own smoking. Specifically, the estimates in Tables 3 and 4 suggest that any improvement in outcomes for workers in Ontario over this time period should be primarily observed among blue collar workers if they are to be attributed to causal effects of smoking bans.

We present the reduced form evidence on these questions in Table 5, which offers estimates on the main SHS exposure and smoking outcome variables of interest separately by broad occupational grouping. The format of Table 5 follows the previous tables, in that each row presents a different outcome and each column is a different occupation-specific sample. Specifically, we present results pertaining to SHS exposure in the top and second rows, while the bottom row presents results for the likelihood of being a current smoker. Column 1 presents results for blue collar workers, Column 2 presents results for other workers, and Column 3 presents results for retired persons and homemakers (whose smoking behavior should not have been directly affected by the local smoking ordinances).

The results in Column 1 of Table 5 confirm that local smoking by-laws - and by implication workplace smoking bans - were effective at improving SHS outcomes for blue collar workers. Specifically, we find in the top row that a local workplace by-law significantly increased the likelihood of reporting zero days of SHS exposure at work by 12 percentage points for blue collar workers. Similarly, in the second row of Column 1 we find that a local workplace by-law reduced the likelihood of reporting 5 or more days of SHS exposure per week by 11 
percentage points, again statistically significant at the five percent level. ${ }^{17}$ That these observed improvements are causal effects of the bans is further supported by the wrong-signed, smaller, and/or statistically insignificant estimates on those same SHS exposure outcomes for the other (non-blue collar) workers, the group that did not exhibit a substantive relationship between a local by-law and reported worksite smoking policy.

The bottom row of Table 5 presents results for the likelihood of being a current smoker. The estimates in Column 1 for blue collar workers provide support for the idea that workplace smoking by-laws (and by implication, workplace bans) affected own-smoking behavior. Specifically, we find that the probability that blue-collar workers report being a current smoker fell by an estimated 4 percentage points when a by-law was adopted (about 11 percent relative to the pre-reform mean), with very small and statistically insignificant reductions for other workers and non-workers. The magnitude of the estimated reduction in own smoking is large but not implausible. Regression adjusted single equation estimates, for example, suggested that a workplace smoking ban is associated with an 11.3 percentage point reduced likelihood of being a current smoker among blue collar workers. Similarly, working at a site with no restrictions was associated with a 17.2 percentage point increased likelihood of being a current smoker. Evans et al. (1999) used a variety of techniques to show that the cross-sectional relationship between workplace bans and smoking participation was not subject to an omitted variables bias. Their 2SLS estimates (using instruments such as firm size) imply that workplace smoking bans reduce smoking participation by a quarter to a third (see their Table 6). Although our relatively small

\footnotetext{
${ }^{17}$ Note that these large improvements in secondhand smoke exposure also indirectly confirm the results on ban presence. A concern is that local by-laws may simply increase awareness of a smoking restriction by individuals who were previously unaware of the actual policy, even in the presence of no changes in actual restrictions. Because the secondhand smoke exposure question is very objective, we can be more confident that the observed improvements in SHS exposure are real. Because these improvements are systematically associated with the local by-laws, the most straightforward explanation is that the local laws did, in fact, change actual worksite smoking policies for blue collar workers.
} 
sample does not permit us to identify a statistically significant 2SLS estimate of the effect of smoking bans on own smoking, the implied IV estimate is similar to the single equation result and comparable to that found in Evans et al. (2000). This is further complementary evidence that workplace smoking bans do, indeed, reduce smoking. ${ }^{18}$

In Table 6 we subject the blue-collar worker results on SHS exposure and own-smoking behavior to the same battery of robustness checks we implemented for the workplace smoking ban outcomes. The columns of Table 6 correspond exactly to those in Table 4, and the top, middle, and bottom panels reflect the same outcomes as in Table 5 (no SHS exposure, daily SHS exposure, and current smoking behavior, respectively). The patterns of estimates in Table 6 confirm that the local smoking by-laws significantly improved SHS exposure outcomes for blue collar workers. With respect to the "no SHS" and "daily SHS" outcomes, we find that all the estimates in Columns 1-5 are sizable in magnitude and of the expected sign. Moreover, excluding the areas around Toronto (Column 1), controlling for countywide laws (Column 2), and restricting attention to individuals in "changer" communities (Column 3) all return estimates that retain statistical significance at the ten percent level or better for both SHS outcomes. The other exercises - considering only the recent time period since 2000 (Column 4) or allowing for county specific time trends (Column 5) - continue to support the baseline estimates, though they do not retain statistical significance at standard confidence levels. With respect to current smoking behavior in the bottom panel, we find fewer statistically precise effects of the local workplace by-laws, though this is not particularly surprising given that the baseline estimate was similarly insignificant. All of these exercises, however, return sizable estimated reductions in

\footnotetext{
${ }^{18}$ In results not reported, we find that the estimated reduction in current smoking rates is largely driven by reductions in occasional (but not daily) smoking; since daily smokers are more likely to be addicted (and therefore less likely to be sensitive to policy interventions), this further suggests that the estimated reductions in own smoking rates for blue collar workers are "real".
} 
current smoking probability, ranging from 3 to 5.6 percentage points (recall the baseline estimate was a 4.2 percentage point reduction in own smoking).

Some final patterns provide complementary evidence that the estimated effects of the local ordinances on smoking behavior are, in fact, real. Specifically, in Table 7 we present estimates from similarly specified models of equation (1) on a set of outcomes that should plausibly be unrelated to the local smoking ordinances - and by implication workplace smoking bans. In the top panel of Table 7 we show results for the probability the individual reports driving after having consumed at least two drinks in the past 30 days, in the middle panel we consider the probability an individual reports fair or poor self-rated general health, and in the bottom panel we show estimates for the probability the individual reports that she felt more unhappy than usual in the past few weeks. ${ }^{19}$ While one could argue that these outcomes could be plausibly affected through effects on own smoking behavior, such effects would be indirect and should arguably be smaller than the estimated smoking reductions. If we observed sizable improvements in these variables associated with local workplace by-laws, for example, this would call into question our estimated improvements on SHS exposure and own-smoking outcomes, perhaps suggesting specification error or other unobserved coincident public health campaigns.

We report estimates for these outcomes in Table 7, whose format exactly follows Tables 4 and 6 with one small change: in Column " 0 " we report the baseline difference in differences estimate. The overall pattern of estimates in Table 7 strongly suggests that our estimated

\footnotetext{
19 An important consideration in choosing these "control" outcomes was the time frame of the question. Specifically, we restricted attention to outcomes pertaining to current or very recent conditions. This is why we chose, for example, not to consider overall alcohol use - the drinking question was asked using a time window of "past year". Also, there is more solid evidence on the structural relationships between smoking and drinking (certainly when compared to the outcomes we consider here); Picone, Sloan, and Trogdon (2004), for example, find that smoking bans reduce alcohol consumption among older individuals, and a large body of work shows drinking and smoking to be strongly complementary behaviors.
} 
improvements in SHS and smoking outcomes for blue collar workers are not spurious. Specifically, across all the "control" outcomes we consider, the vast majority of estimates on the local by-law indicator are substantively zero and never statistically significant. Moreover, the sign of the estimates in the top and bottom rows is not consistent across specifications. While the estimates in the middle panel for the likelihood of reporting fair or poor health all have the same sign (positive), this actually suggests worsening health. These overall patterns of null findings for outcomes that should plausibly be further removed from the changes in smoking bans induced by the local smoking ordinances provide strong support for our interpretation that the local by-laws improved SHS and smoking outcomes for blue collar workers.

\section{Conclusion}

Understanding whether and how much state and local smoking ordinances affect SHS exposure and own smoking is crucial for a comprehensive evaluation of the costs and benefits of such ordinances, particularly since public health benefits are routinely touted as the main motivation for these laws. Unfortunately, most previous research has relied on cross-sectional variation, which may reflect unobserved characteristics correlated both with the decision to adopt a ban and decisions regarding own smoking and type of workplace. We have revisited this question using detailed outcome data from Ontario, Canada and substantial variation in the timing of adoption of over 100 local by-laws over the period 1997-2004. Our data are particularly attractive because - in addition to SHS exposure and own smoking outcomes - we observe the respondent's description of her worksite's smoking policies. This allows us to directly estimate the underlying "first stage" relationship between local policy adoption and subsequent worksite 
smoking policies. Previous research has implicitly assumed that these ordinances are binding; that is, that all workers are "treated" when bans are adopted.

We confirm that local by-laws increase reported ban presence along several different dimensions. This positive relationship survives inclusion of unrestricted county dummies to account for time-invariant unobserved heterogeneity. Importantly, however, we demonstrate that the aggregate benefits of local by-law adoption with respect to reported ban presence are driven entirely by blue collar workers. Other workers - the vast majority of whom were already working at job sites with strict workplace smoking policies well before the period of local by-law adoption - experienced no marginal increase in ban presence when local by-laws were adopted. While intuitive, this is a new finding in the literature and suggests that recent movements toward occupation specific bans in hospitality occupations (including bars and restaurants) may have overlooked an important group of workers who would benefit from increased protection.

We also demonstrate that the large increases in reported ban presence experienced by laborers were associated with significant improvements in health outcomes. Specifically, we estimate that a local workplace by-law reduced the likelihood of reporting daily SHS exposure by about 30 percent. Measured differently, we find that a local by-law increased the likelihood of reporting no SHS exposure at work by 25 percent among these workers. Estimates for ownsmoking behavior confirm that workplace smoking bans reduce own smoking. Overall, our results provide important new insight into the underlying mechanisms through which smoking bans improve outcomes. Future research evaluating the effects of state and province-wide bans must take care to account for these pre-existing improvements associated with local by-laws in order to produce accurate estimates. 


\section{References}

Bertrand, M., E. Duflo, and S. Mullainathan (2004). "How Much Should We Trust Difference in Differences Estimates?," Quarterly Journal of Economics, 119(1): 249-275.

Brownson, R., D. Hopkins and M. Wakefield (2002). "Effects of Smoking Restrictions in the Workplace," Annual Review of Public Health, 23: 333-348.

Brownson, R., M. Eriksen, R. Davis, and K. Warner (1997). "Environmental Tobacco Smoke: Health Effects and Policies to Reduce Exposure," Annual Review of Public Health, 18: 163-185.

Chaloupka, F. (1992). "Clean indoor air laws, addiction, and cigarette smoking," Applied Economics, 24: 193-205.

Coghlin, J., S. Hammond, and P. Gann (1989). "Development of epidemiologic tools for measuring environmental tobacco smoke exposure," American Journal of Epidemiology, 130: 696-704.

Emont, S., W. Choi, T. Novotny, and G. Giovino (1993). "Clean indoor air legislation, taxation, and smoking behaviour in the United States: an ecological analysis," Tobacco Control, 2: 13-17.

Evans, W., Farrelly, M., and E. Montgomoery (1999). "Do Workplace Smoking Bans Reduce Smoking?," American Economic Review, 89(4): 728-747.

Fichtenberg, C. and S. Glantz (2004). "Effect of smoke-free workplaces on smoking behavior: systematic review," British Medical Journal, 325: 188-194.

Friedberg, L. (1998). "Did Unilateral Divorce Raise Divorce Rates? Evidence from Panel Data," American Economic Review, 83 (3): 525-548.

Gerlach, K., D. Shopland, A. Hartman, J. Gibson, and T. Pechacek (1997). "Workplace smoking policies in the United States: results from a national survey of more than 100,000 workers," Tobacco Control, 6: 199-206.

Hammond, D., P. McDonald, G. Fong, K. Brown, and R. Cameron (2004). "The Impact of Cigarette Warning Labels and Smoke-free Bylaws on Smoking Cessation: Evidence from Former Smokers," Canadian Journal of Public Health, 95(3): 201-204.

Keeler, T., T. Hu, P. Barnett, and W. Manning (1993). “Taxation, Regulation, and addiction: a demand function for cigarettes based on time-series evidence," Journal of Health Economics, 12: 1-18.

Levy, D. and K. Friend (2003). "The effects of clean indoor air laws: what do we know and what do we need to know?," Health Education Research, 18(5): 592-609. 
Longo, D., M. Feldman, R. Kruse, R. Brownson, G. Petroski, and J. Hewett (1998). "Implementing Smoking Bans in American Hospitals: Results of a National Survey," Tobacco Control, 7: 47-55.

Moskowitz, J., Z. Lin, and E. Hudes (2000). "The impact of workplace smoking ordinances in California on smoking cessation," American Journal of Public Health, 90(5): 757-761.

Nelson, D., S. Emont, R. Brackbill, L. Cameron, J. Peddicord, and M. Fiore (1994). “Cigarette smoking prevalence by occupation in the United States: A comparison between 1978 to 1980 and 1987 to 1990," Journal of Occupational Medicine, 36(5): 516-525.

Picone, G., F. Sloan, and J. Trogdon (2004). "The Effect of the Tobacco Settlement and Smoking Bans on Alcohol Consumption," Health Economics, 13: 1063-1080.

Pierce, J., E. Gilpin, S. Emery, M. White, B. Rosbrook, C. Berry, and A. Farkas (1998). "Has the California Tobacco Control Program Reduced Smoking?," Journal of the American Medical Association, 280(10): 893-899.

Pierce, J., T. Shanks, M. Pertschuk, E. Gilpin, D. Shopland, M. Johnson, and D. Bal (1994). "Do smoking ordinances protect non-smokers from environmental tobacco smoke at work?," Tobacco Control, 3: 15-20.

Shopland, D., C. Anderson, D. Burns, and K. Gerlach (2004). "Disparities in Smoke-Free Workplace Policies Among Food Service Workers," Journal of Occupational and Environmental Medicine, 46(4): 347-356.

Shopland, D., K. Gerlach, D. Burns, A. Hartman, and J. Gibson (2001). "State-specific trends in smoke-free workplace policy coverage: the current population survey tobacco use supplement, 1993 to 1999," Journal of Occupational and Environmental Medicine, 43: 680-686.

Siegel, M., A. Albers, D. Cheng, L. Biener, and N. Rigotti (2004). "Effect of Local Restaurant Smoking Regulations on Environmental Tobacco Smoke Exposure Among Youths," American Journal of Public Health, 94(2): 321-325.

Siegel, M. and M. Skeer (2002). "Exposure to secondhand smoke and excess lung cancer mortality risk among workers in the "5 B's": bars, bowling alleys, billiard halls, betting establishments, and bingo parlours," Tobacco Control, 12: 333-338.

Stephens, T., Linda Pederson, J. Koval, and C. Kim (1997). “The Relationship of Cigarette Prices and No-Smoking Bylaws to the Prevalence of Smoking in Canada," American Journal of Public Health, 87(9): 1519-1521.

Tauras, J. (2005). "The Impact of Smoke Free Air Laws and Cigarette Prices on Adult Cigarette Demand," Economic Inquiry, 44: 333-342. 
United States Census Bureau (2006). "Census 2000 PHC-T-40. Estimated Daytime Population and Employment-Residence Ratios: 2000," report available at http://www.census.gov/population/www/socdemo/daytime/daytimepop.html.

Wasserman, J., W. Manning, J. Newhouse, and J. Winkler (1991). "The effects of excise taxes and regulations on cigarette smoking," Journal of Health Economics, 10: 43-64.

Wortley, P., R. Caraballo, L. Pederson, and T. Pechacek (2002). "Exposure to Secondhand Smoke in the Workplace: Serum Cotinine by Occupation," Journal of Occupational and Environmental Medicine, 44(6): 503-509.

Yurkeli, A. and P. Zhang (2000). "The impact of clean indoor-air laws and cigarette smuggling on demand for cigarettes: An empirical model," Health Economics, 9: 159-170. 


\section{Table 1}

Descriptive Statistics, CAMH Monitor 1997-2004

\begin{tabular}{|c|c|c|c|}
\hline Variable & Full Sample & Local By-Law $=0$ & Local By-Law $=1$ \\
\hline Age & $39.2(.176)$ & $39.2(.203)$ & $39.1(.362)$ \\
\hline Male & $.53(.007)$ & $.53(.008)$ & $.54(.016)$ \\
\hline Less than HS & $.10(.004)$ & $.11(.005)$ & $.05(.007)$ \\
\hline HS degree & $.25(1.006)$ & $.26(.007)$ & $.22(.013)$ \\
\hline Some college & $.34(.007)$ & $.35(.008)$ & $.31(.015)$ \\
\hline University degree & $.31(.007)$ & $.28(.008)$ & $.40(.016)$ \\
\hline Married & $.66(.007)$ & $.69(.008)$ & $.59(.016)$ \\
\hline Never married & $.24(.007)$ & $.22(.008)$ & $.30(.015)$ \\
\hline Blue collar worker & $.30(007)$ & $.31(.008)$ & $.27(.014)$ \\
\hline Other worker & $.70(.007)$ & $.69(.008)$ & $.73(.014)$ \\
\hline Work area ban & $.74(.007)$ & $.70(.008)$ & $.84(.012)$ \\
\hline Ban range & $2.82(.011)$ & $2.77(.013)$ & $2.95(.021)$ \\
\hline No work restrictions & $.07(.004)$ & $.08(.005)$ & $.04(.006)$ \\
\hline No SHS Exposure & $.66(.009)$ & $.64(.011)$ & $.69(.015)$ \\
\hline Daily SHS Exposure & $.20(.008)$ & $.21(.009)$ & $.17(.012)$ \\
\hline Smoker & $.29(.007)$ & $.30(.008)$ & $.25(.014)$ \\
\hline $\mathrm{N}$ & 5917 & 4620 & 1297 \\
\hline
\end{tabular}

Weighted means, workers only. 
Table 2:

Local By-laws Toughened Workplace Smoking Restrictions Models Include County and Year Fixed Effects CAMH Monitor 1997-2004

\begin{tabular}{l|c|c|c}
\hline & All & Males & Females \\
\hline Work Area Ban & $.039^{* *}$ & $.086^{* * *}$ & -.019 \\
Local workplace by-law & $(.017)$ & $(.020)$ & $(.028)$ \\
& & & .120 \\
$\mathrm{R}-$ Squared & 5917 & 2930 & .076 \\
$\mathrm{~N}$ & $.065^{* *}$ & $.126^{* * *}$ & 2987 \\
\hline Ban Range & $(.029)$ & $(.040)$ & -.017 \\
Local workplace by-law & .105 & .105 & $.067)$ \\
& 5917 & 2930 & .065 \\
R-Squared & $-.024 * *$ & $-.048^{* * *}$ & 2987 \\
$\mathrm{~N}$ & $(.009)$ & $(.012)$ & .006 \\
\hline No Work Restriction & & $.015)$ \\
Local workplace by-law & .057 & 2930 & .034 \\
& 5917 & 2987 \\
\hline
\end{tabular}

Data come from restricted use versions of the 1997-2004 CAMH monitor. Work area ban is an indicator equal to one if smoking is allowed only outside or not at all on company property and zero otherwise. Ban Range is an index where 1 indicates that smoking is allowed anywhere and 4 indicates that smoking is not allowed anywhere on company property. No work restriction is an indicator that equals one if smoking is allowed anywhere at work and zero otherwise. Estimates are from OLS regressions that control for county and year fixed effects and demographic characteristics (age, sex, education -4 categories, and marital status -3 categories). Standard errors below in parentheses, clustered by county. Sample excludes individuals reporting they don't know or refused a response to the question about workplace smoking restrictions. *** Significant at $1 \%, * *$ Significant at $5 \%, *$ Significant at $10 \%$. 


\section{Table 3:}

The Effects are Entirely Driven by Blue-Collar Workers

Models Include County and Year Fixed Effects

CAMH Monitor 1997-2004

\begin{tabular}{l|cc}
\hline & Blue Collar Workers & Other Workers \\
\hline Work Area Ban & .537 & .774 \\
Pre-reform mean & $.111^{* * *}$ & .011 \\
Local workplace by-law & $(.037)$ & $(.019)$ \\
& & .077 \\
R-Squared & .122 & 4162 \\
$\mathrm{~N}$ & 1755 & 2.92 \\
\hline Ban Range & 2.45 & -.006 \\
Pre-reform mean & $.235^{* * *}$ & $(.036)$ \\
Local workplace by-law & $(.063)$ & .069 \\
& & 4162 \\
R-Squared & .111 & .032 \\
$\mathrm{~N}$ & 1755 & .004 \\
\hline No work restrictions & .172 & $(.011)$ \\
Pre-reform mean & $-.093^{* * *}$ & .029 \\
Local workplace by-law & $(.020)$ & 4162 \\
\hline R-Squared & .083 & \\
$\mathrm{~N}$ & 1755 & \\
\hline Seec & & \\
\hline
\end{tabular}

See notes to Table 2 . 
Table 4:

Robustness of By-Law Effect on Ban Presence, Blue-Collar Workers Models Include County and Year Fixed Effects

CAMH Monitor 1997-2004

\begin{tabular}{|c|c|c|c|c|c|}
\hline & $\begin{array}{c}(1) \\
\text { Exclude } \\
\text { Peel, York, } \\
\text { and Durham } \\
\text { residents } \\
\text { (around } \\
\text { Toronto) }\end{array}$ & $\begin{array}{c}\text { (2) } \\
\text { Control only } \\
\text { for county- } \\
\text { wide by-laws }\end{array}$ & $\begin{array}{c}\text { (3) } \\
\text { Only residents } \\
\text { in localities } \\
\text { adopting a by- } \\
\text { law } \\
\text { (changers) }\end{array}$ & $\begin{array}{c}(4) \\
\text { Only } 2000 \text { - } \\
2004\end{array}$ & $\begin{array}{c}\text { (5) } \\
\text { Baseline }+ \\
\text { county } \\
\text { specific time } \\
\text { trends }\end{array}$ \\
\hline \multicolumn{6}{|l|}{ Work area ban } \\
\hline Local workplace by-law & $\begin{array}{c}.122 * * * \\
(.045)\end{array}$ & $\begin{array}{c}.106 * * * \\
(.035)\end{array}$ & $\begin{array}{c}.123 * * * \\
(.043)\end{array}$ & $\begin{array}{c}.141 * * * \\
(.050)\end{array}$ & $\begin{array}{l}.104 * * \\
(.048)\end{array}$ \\
\hline R-squared & .119 & .121 & .133 & .169 & .145 \\
\hline $\mathrm{N}$ & 1548 & 1755 & 1436 & 913 & 1755 \\
\hline \multicolumn{6}{|l|}{ Ban Range } \\
\hline Local workplace by-law & $\begin{array}{c}.242 * * * \\
(.076)\end{array}$ & $\begin{array}{c}.268 * * * \\
(.067)\end{array}$ & $\begin{array}{c}.274 * * * \\
(.069)\end{array}$ & $\begin{array}{l}.292 * * \\
(.110)\end{array}$ & $\begin{array}{l}.222 * * \\
(.088)\end{array}$ \\
\hline R-squared & .106 & .110 & .124 & .158 & .128 \\
\hline $\mathrm{N}$ & 1548 & 1755 & 1436 & 913 & 1755 \\
\hline \multicolumn{6}{|l|}{ No Work Restrictions } \\
\hline Local workplace by-law & $\begin{array}{c}-.084 * * * \\
(.023)\end{array}$ & $\begin{array}{c}-.111 * * * \\
(.023)\end{array}$ & $\begin{array}{c}-.102 * * * \\
(.023)\end{array}$ & $\begin{array}{c}-.126^{* * *} \\
(.039)\end{array}$ & $\begin{array}{c}-.088^{* * * *} \\
(.025)\end{array}$ \\
\hline R-squared & .080 & .083 & .089 & .115 & .101 \\
\hline $\mathrm{N}$ & 1548 & 1755 & 1436 & 913 & 1755 \\
\hline
\end{tabular}

See notes to Table 2 . 
Table 5:

\section{Local By-laws Reduced SHS Exposure for Blue Collar Workers}

Models Include County and Year Fixed Effects

CAMH Monitor 1997-2004

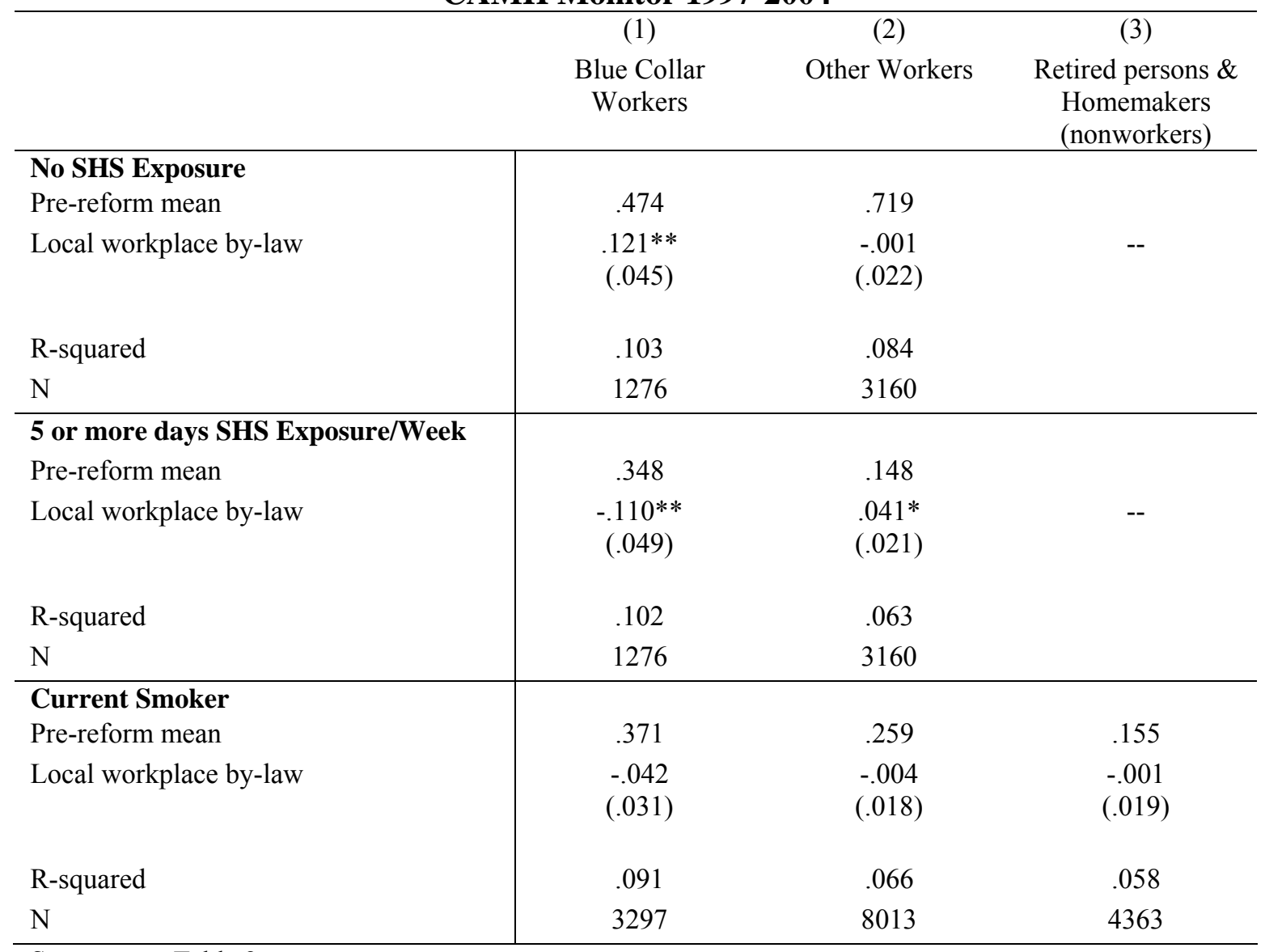

See notes to Table 2 . 
Table 6:

Robustness of By-Law Effect on SHS and Smoking Outcomes, Blue-Collar Workers Models Include County and Year Fixed Effects CAMH Monitor 1997-2004

\begin{tabular}{|c|c|c|c|c|c|}
\hline & $\begin{array}{c}(1) \\
\text { Exclude } \\
\text { Peel, York, } \\
\text { and Durham } \\
\text { residents } \\
\text { (around } \\
\text { Toronto) } \\
\end{array}$ & $\begin{array}{l}\text { (2) } \\
\text { Control only } \\
\text { for county- } \\
\text { wide by-laws }\end{array}$ & $\begin{array}{c}\text { (3) } \\
\text { Only residents } \\
\text { in localities } \\
\text { adopting a by- } \\
\text { law } \\
\text { (changers) }\end{array}$ & $\begin{array}{l}(4) \\
\text { Only } 2000- \\
2004\end{array}$ & $\begin{array}{c}(5) \\
\text { Baseline }+ \\
\text { county } \\
\text { specific time } \\
\text { trends }\end{array}$ \\
\hline \multicolumn{6}{|l|}{ No SHS Exposure } \\
\hline Local workplace by-law & $\begin{array}{l}.133 * * \\
(.052)\end{array}$ & $\begin{array}{l}.144 * * \\
(.064)\end{array}$ & $\begin{array}{c}.128^{* * * *} \\
(.048)\end{array}$ & $\begin{array}{l}.122 \\
(.075)\end{array}$ & $\begin{array}{l}.087 \\
(.056)\end{array}$ \\
\hline R-squared & .105 & .103 & .111 & .125 & .144 \\
\hline $\mathrm{N}$ & 1137 & 1276 & 1041 & 911 & 1276 \\
\hline $\begin{array}{l}5 \text { or more days SHS } \\
\text { Exposure/Week } \\
\text { Local workplace by-law }\end{array}$ & $\begin{array}{c}-.120 * * \\
(.053)\end{array}$ & $\begin{array}{l}-.120^{*} \\
(.061)\end{array}$ & $\begin{array}{l}-.094 * \\
(.051)\end{array}$ & $\begin{array}{l}-.063 \\
(.076)\end{array}$ & $\begin{array}{l}-.048 \\
(.053)\end{array}$ \\
\hline R-squared & .100 & .101 & .106 & .126 & .141 \\
\hline $\mathrm{N}$ & 1137 & 1276 & 1041 & 911 & 1276 \\
\hline \multicolumn{6}{|l|}{ Current Smoker } \\
\hline Local workplace by-law & $\begin{array}{l}-.056^{*} \\
(.031)\end{array}$ & $\begin{array}{l}-.039 \\
(.029)\end{array}$ & $\begin{array}{l}-.030 \\
(.035)\end{array}$ & $\begin{array}{l}-.045 \\
(.041)\end{array}$ & $\begin{array}{l}-.055 \\
(.036)\end{array}$ \\
\hline R-squared & .089 & .090 & .089 & .092 & .102 \\
\hline $\mathrm{N}$ & 2928 & 3297 & 2648 & 1925 & 3297 \\
\hline
\end{tabular}

See notes to Table 2 . 


\section{Table 7:}

“Control” Outcomes, Blue-Collar Workers

Models Include County and Year Fixed Effects

CAMH Monitor 1997-2004

\begin{tabular}{|c|c|c|c|c|c|c|}
\hline & $\begin{array}{c}(0) \\
\text { Baseline }\end{array}$ & $\begin{array}{c}(1) \\
\text { Exclude } \\
\text { Peel, York, } \\
\text { and Durham } \\
\text { residents } \\
\text { (around } \\
\text { Toronto) } \\
\end{array}$ & $\begin{array}{c}\text { (2) } \\
\text { Control only } \\
\text { for county- } \\
\text { wide by-laws }\end{array}$ & $\begin{array}{c}(3) \\
\text { Only } \\
\text { residents in } \\
\text { localities } \\
\text { adopting a } \\
\text { by-law } \\
\text { (changers) }\end{array}$ & $\begin{array}{c}\text { (4) } \\
\text { Only } 2000 \\
-2004\end{array}$ & $\begin{array}{c}(5) \\
\text { Baseline }+ \\
\text { county } \\
\text { specific time } \\
\text { trends }\end{array}$ \\
\hline $\begin{array}{l}\text { Drove in past } 30 \text { days } \\
\text { after drinking } 2+ \\
\text { drinks (mean=.049) } \\
\text { Local workplace by-law }\end{array}$ & $\begin{array}{c}-.003 \\
(.024)\end{array}$ & $\begin{array}{l}.003 \\
(.026)\end{array}$ & $\begin{array}{c}-.003 \\
(.028)\end{array}$ & $\begin{array}{l}-.007 \\
(.025)\end{array}$ & $\begin{array}{l}-.018 \\
(.024)\end{array}$ & $\begin{array}{c}.002 \\
(.024)\end{array}$ \\
\hline R-squared & .046 & .050 & .046 & .047 & .051 & .066 \\
\hline $\mathrm{N}$ & 3297 & 2928 & 3297 & 2648 & 1925 & 3297 \\
\hline $\begin{array}{l}\text { Fair/Poor self rated } \\
\text { health (mean=.067) } \\
\text { Local workplace by-law }\end{array}$ & $\begin{array}{c}.015 \\
(.014)\end{array}$ & $\begin{array}{l}.020 \\
(.015)\end{array}$ & $\begin{array}{c}.001 \\
(.018)\end{array}$ & $\begin{array}{c}.013 \\
(.015)\end{array}$ & $\begin{array}{l}.010 \\
(.023)\end{array}$ & $\begin{array}{l}.011 \\
(.018)\end{array}$ \\
\hline R-squared & .040 & .045 & .040 & .039 & .059 & .060 \\
\hline $\mathrm{N}$ & 2347 & 2087 & 2347 & 1880 & 1923 & 2347 \\
\hline $\begin{array}{l}\text { Past few weeks feel } \\
\text { more unhappy than } \\
\text { usual (mean=.086) } \\
\text { Local workplace by-law }\end{array}$ & $\begin{array}{l}-.0001 \\
(.019)\end{array}$ & $\begin{array}{l}-.003 \\
(.020)\end{array}$ & $\begin{array}{l}.015 \\
(.021)\end{array}$ & $\begin{array}{c}.008 \\
(.020)\end{array}$ & $\begin{array}{c}.002 \\
(.027)\end{array}$ & $\begin{array}{l}-.009 \\
(.023)\end{array}$ \\
\hline R-squared & .046 & .046 & .047 & .045 & .036 & .073 \\
\hline $\mathrm{N}$ & 1929 & 1719 & 1929 & 1541 & 1505 & 1929 \\
\hline
\end{tabular}

See notes to Table 2. Fair/poor self rated health and unhappiness questions were only asked 1999-2004. 


\begin{tabular}{|c|c|}
\hline $\begin{array}{r}\text { Expanded } \\
\text { Model is LPM of Work Are } \\
\text { CAM }\end{array}$ & $\begin{array}{l}\text { Fixed Effects, All Adults } \\
004\end{array}$ \\
\hline Variable & Estimate \\
\hline Local By-law & $\begin{array}{l}.039 * * \\
(.017)\end{array}$ \\
\hline 1998 & $\begin{array}{l}.005 \\
(.027)\end{array}$ \\
\hline 1999 & $\begin{array}{l}.037^{*} \\
(.020)\end{array}$ \\
\hline 2000 & $\begin{array}{c}.058 * * * \\
(.016)\end{array}$ \\
\hline 2001 & $\begin{array}{l}.051 * * \\
(.023)\end{array}$ \\
\hline 2002 & $\begin{array}{l}.071 * * \\
(.027)\end{array}$ \\
\hline 2003 & $\begin{array}{c}.122^{* * *} \\
(.021)\end{array}$ \\
\hline 2004 & $\begin{array}{c}.177^{* * *} * \\
(.021)\end{array}$ \\
\hline Age & $\begin{array}{c}.001 * \\
(.0001)\end{array}$ \\
\hline Male & $\begin{array}{c}-.109 * * * \\
(.015)\end{array}$ \\
\hline Previously married & $\begin{array}{c}.002 \\
(.026)\end{array}$ \\
\hline Never married & $\begin{array}{l}-.010 \\
(.014)\end{array}$ \\
\hline HS degree & $\begin{array}{l}.044^{*} \\
(.022)\end{array}$ \\
\hline Some college & $\begin{array}{l}.104 * * * \\
(.027)\end{array}$ \\
\hline University degree or more & $\begin{array}{c}.200 * * * \\
(.041)\end{array}$ \\
\hline R-Squared & .106 \\
\hline N & $591 /$ \\
\hline
\end{tabular}




\section{Figure 1.}

Map of Ontario County/Regional Municipality/District Boundaries

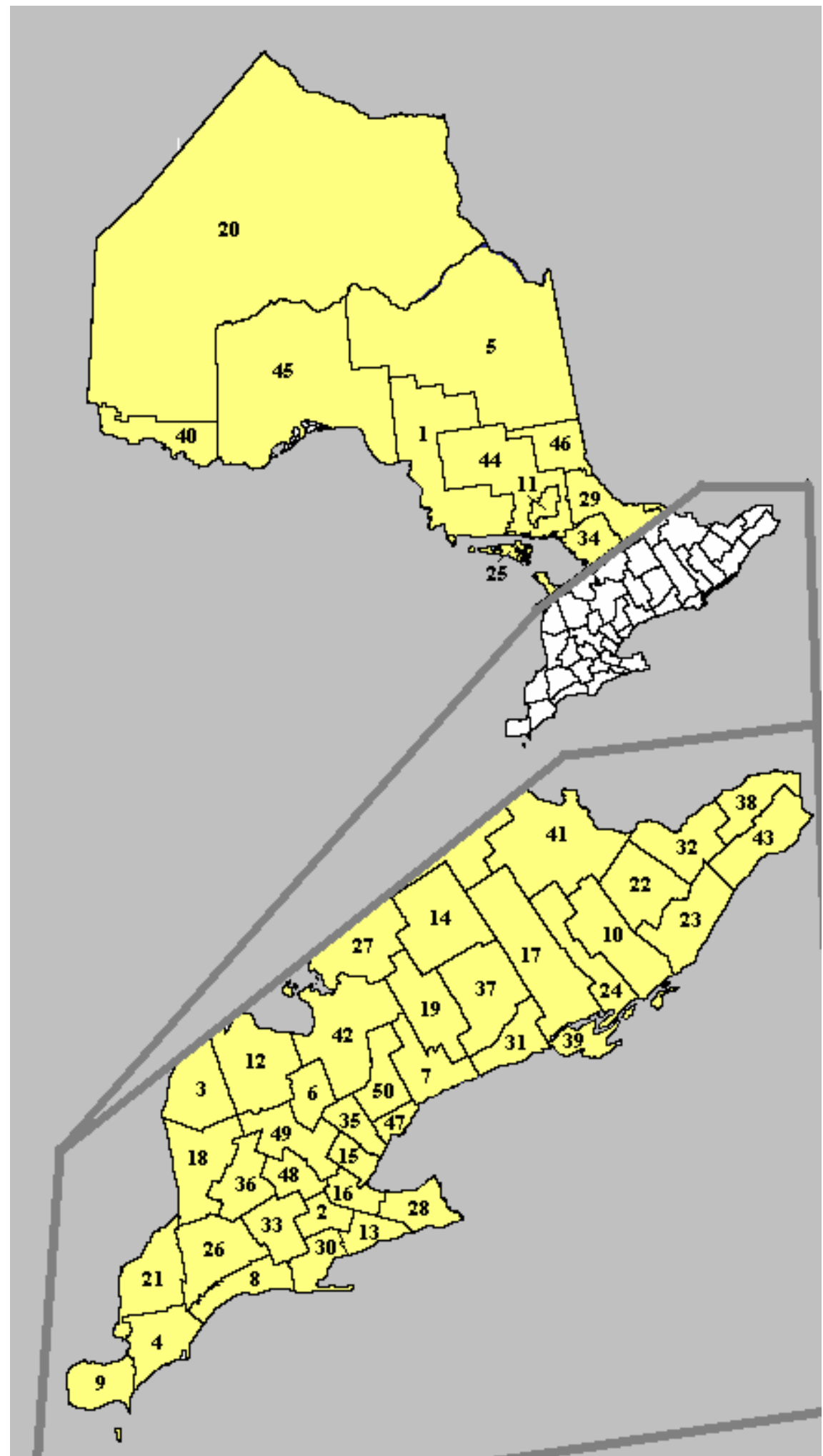

*To provide a sense of size, note that Toronto (\#47) covers apx. 700 square kilometers. 


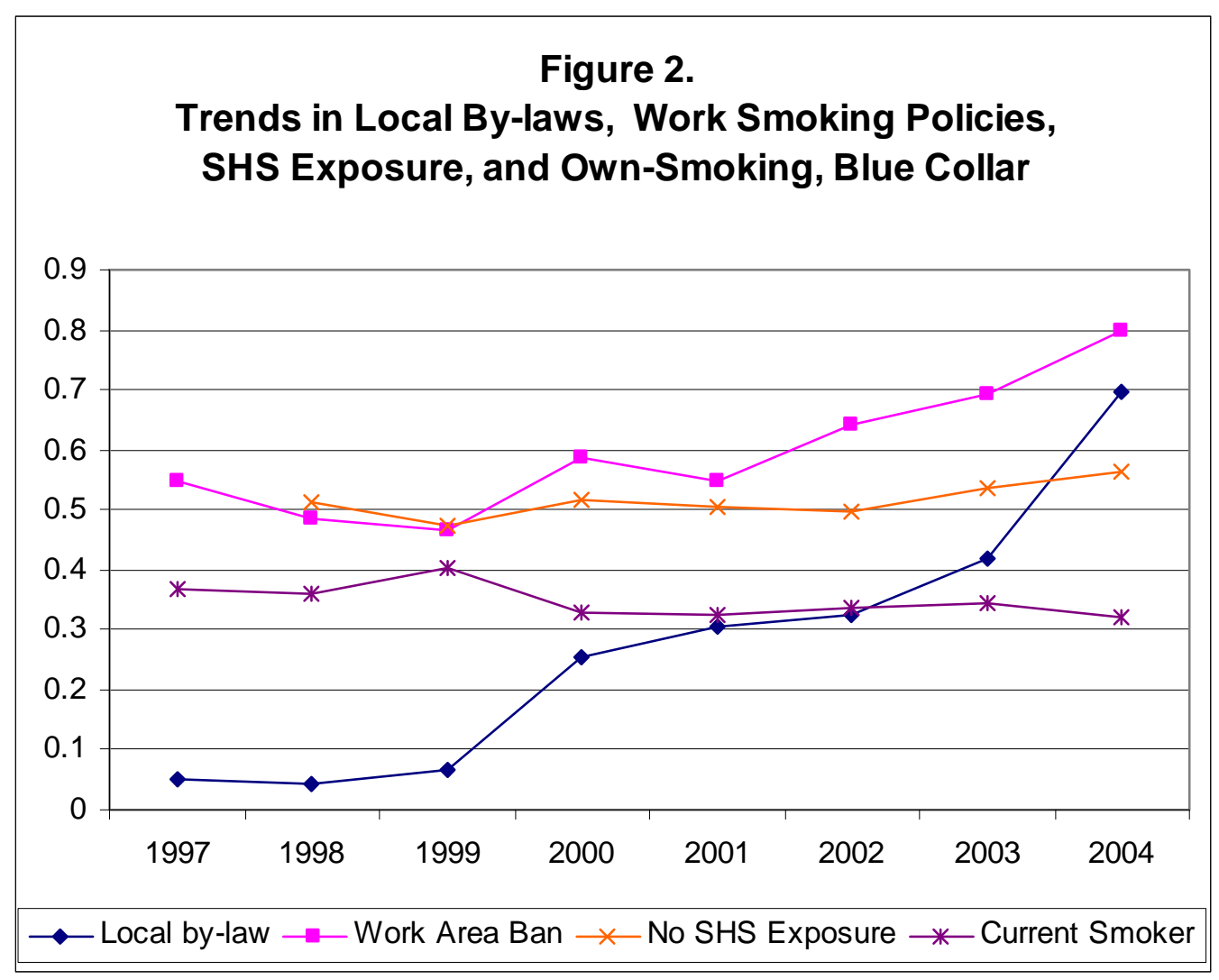




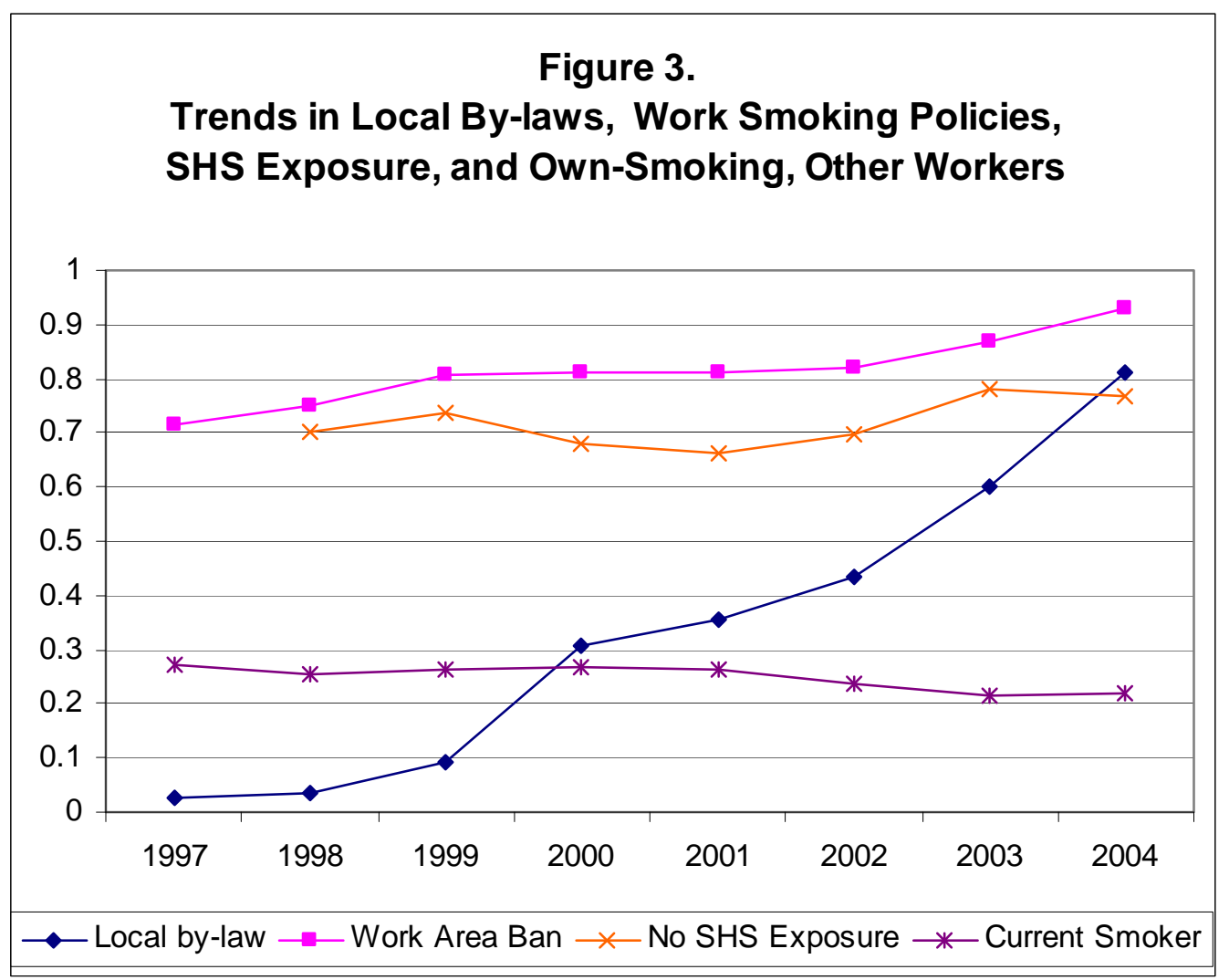


Figure 4.

Trends in Work Area Ban, by Occupation

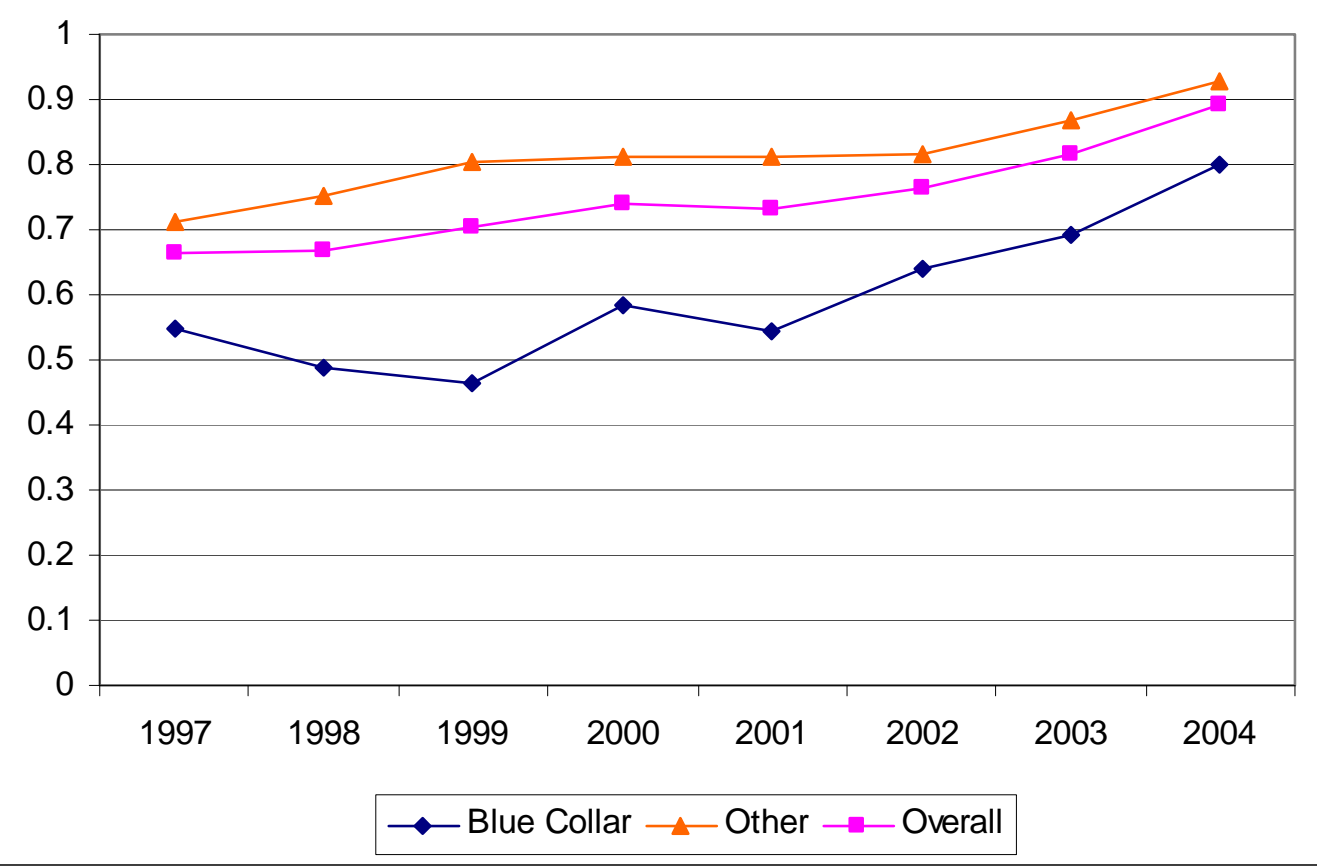

